\title{
ESTRUCTURA DEL TEXTO DESCRIPTIVO DE PRODUCTOS FARMACÉUTICOS DIFUNDIDOS POR MEDIO DE INTERNET ${ }^{1}$
}

\author{
Ana María Burdach Rudloff \\ Hernán Pons Galea
}

\begin{abstract}
RESUMEN
El artículo describe y analiza la estructuración del texto descriptivo de los avisos publicitarios farmacéuticos difundidos a través de Internet. El foco del estudio es evidenciar los recursos formales y estilísticos utilizados para promocionar, persuadir y convencer a un público anónimo y heterogéneo acerca de las supuestas bondades de productos potencialmente peligrosos.

Palabras clave: Internet, drogas, texto descriptivo, recursos persuasivos, publicidad.
\end{abstract}

\begin{abstract}
This article describes and analyzes the structure of descriptive texts dealing with pharmaceutical ads distributed through Internet. The focus of the study is to reveal the formal and stylistic resources used to publicize, persuade and convince an anonymous and heterogeneous audience about the alleged benefits of potentially dangerous products.

Key words: Internet, drugs, descriptive text, persuasion resources, publicity.
\end{abstract}

Ph. D. Ana María Burdach Rudloff. Lingüística y Filología Hispánicas, Universidad de Valladolid, España. Correo electrónico: aburdach@uc.cl

M. Sc. Hernán Pons Galea. State University New York, U.S.A.

Correo electrónico: hpons@uc.cl

Recepción: 29-8-06

Aceptación: 28-11-06 


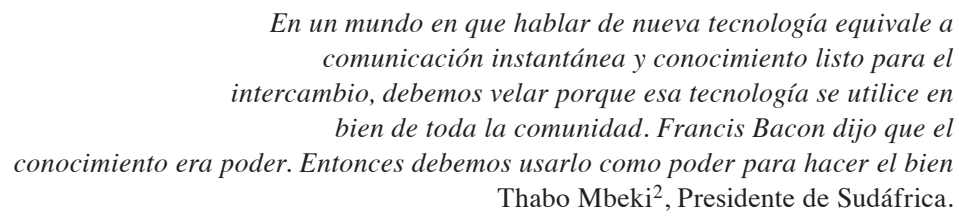

\section{Introducción}

El 'tráfico cibernético' de drogas o sustancias controladas se ha convertido en un problema inmanejable para muchos gobiernos del mundo, a cuyos territorios ingresan cada vez más medicamentos o sustancias peligrosas, bajo la frecuente apariencia de productos dietéticos, suplementos vitamínicos, energizantes o inhibidores del apetito, entre otros.

La Oficina de Control de Drogas de las Naciones Unidas (UNODC) asegura que más de 60 países han reportado esta actividad ilícita, entre ellos Estados Unidos y varias naciones europeas. Incluso la Junta Internacional de Fiscalización de Estupefacientes (JIFE), con sede en Viena, ha pedido a los gobiernos "buscar maneras más eficientes para bloquear el tráfico por Internet".

Este problema plantea una nueva dimensión del "fenómeno social de la droga", ámbito que resulta naturalmente esquivo y peligroso, especialmente por su naturaleza anónima y clandestina, ya que se distribuye mediante correos electrónicos masivos sin discriminación de edad, sexo, condición socio-económica o nivel cultural del destinatario meta. Una variante de esta oferta a través de Internet la constituye el envío de mensajes de productos seudo farmacéuticos que contienen sustancias que han sido prohibidas por las legislaciones de varios países y que se ofrecen sin prescripción médica ni límite de expendio.

Estas campañas apuntan a un cliente potencial y ofrecen productos aparentemente inocuos, bajo la apariencia de un inocente "suplemento vitamínico", presentado en un seductor envoltorio descriptivo, que exalta y exagera las características beneficiosas del producto. En la realidad, estos medicamentos pueden conllevar un riesgo de seria adicción, efectos colaterales nocivos e incluso la muerte. La facilidad con que se pueden adquirir y el hecho de no necesitar prescripción ${ }^{4}$ y , hacen de esta actividad una atractiva tentación para un público desinformado, tales como jóvenes deportistas que buscan un desarrollo muscular acelerado, personas que aspiran a una pérdida rápida de peso, ejecutivos que pretenden lograr una hiperproductividad en su trabajo o público general, que requiere controlar fácilmente algunas patologías comunes.

Este nuevo fenómeno, derivado del vertiginoso desarrollo tecnológico que han experimentado las comunicaciones en los últimos años, amenaza "con alterar el equilibrio estratégico internacional, deteriora la productividad, eleva sideralmente los costos sanitarios y sociales, destruyendo al sujeto de toda geopolítica: el hombre, y al mismo tiempo, el andamiaje democrático, por la corrupción y la criminalidad que le resultan sus indispensables socias" (Escobar, R.T. 2003) ${ }^{6}$.

Todo ello se realiza a través del empleo de estrategias publicitarias persuasivas clave que incitan a la adquisición del producto. Con este fin, el enunciador realiza una cuidadosa selección del léxico, crea una atractiva disposición de los enunciados, configura una eficaz utilización de estrategias persuasivas -lingüístico-discursivas, semánticas, de coherencia local, pragmáticas y retóricas- y complementa el mensaje lingüístico con apoyos visuales adecuados -imágenes, colores o efectos especiales- a partir de modelos teóricos provenientes de la pragmática, de la lingüística, del análisis del discurso, de la retórica, de la semántica y de la semiótica. En los 
mensajes publicitarios en internet se privilegian formatos más directos, concisos e improvisados, en función del espacio y de la inmediatez del sistema, ya que, como asegura Samaniego (2003),

\footnotetext{
Los nuevos formatos de la cibernética -internet y telefonía celular, principalmente- condicionan, por razones de índole tanto tecnológica como económica, la máxima brevedad de los mensajes. Ambos medios favorecen a la vez que determinan, una comunicación instantánea y veloz, lo que ya de por sí impide o, al menos, no facilita la revisión del mensaje en aspectos de ortografía, redacción y estilo (2003) 7 .
}

De ahí que en este artículo intentemos descubrir los principales rasgos lingüísticos que se interrelacionan para configurar estos mensajes publicitarios masivos distribuidos a través de internet, con el fin de hacer patentes los recursos persuasivos empleados y la estructuración lingüística de sus proposiciones. Con este fin, se seleccionó aleatoriamente un corpus de 30 mensajes publicitarios en inglés, distribuidos masivamente por Internet. Dichos mensajes fueron analizados a la luz del modelo teórico de Adam (1992) con las adecuaciones correspondientes a la naturaleza del corpus.

\section{Antecedentes teóricos}

En la creación de un texto confluyen un sinnúmero de variables que permiten clasificarlo, ya sea como narrativo, descriptivo, expositivo, argumentativo o instructivo. Sin embargo, en la práctica es difícil encontrar textos puramente narrativos, descriptivos o argumentativos, pues, con frecuencia las fronteras entre estos tipos se traslapan y se dificulta la delimitación entre uno y otro tipo.

Entre los tipos de textos que con frecuencia configuran el texto publicitario se encuentran los textos descriptivos. Los textos descriptivos forman, generalmente, parte de textos de mayor entidad, como los argumentativos o narrativos, en los que sirven como soporte o ilustración de estos.

En general, en todo texto descriptivo hay una descripción jerárquica de los elementos descritos. Esta descripción se caracteriza por la presencia de un núcleo más un predicado, del cual frecuentemente se desprenden nuevos núcleos que pueden dar origen a nuevos predicados, lo que permite la progresión del texto. Opera aquí el principio de tema-rema, mediante el cual un elemento del enunciado anterior es seleccionado para constituirse en un nuevo núcleo del predicado, lo que va encadenando los elementos de la descripción, con el fin de captar la atención y el interés del destinatario, depositario último de la intención comunicativa de este tipo de mensajes.

Según Adam (1992), una descripción se apoya en cuatro operaciones fundamentales, donde se combinan las microproposiciones descriptivas: anclaje, aspectualización, puesta en relación y tematización.

\section{Tema-Título}

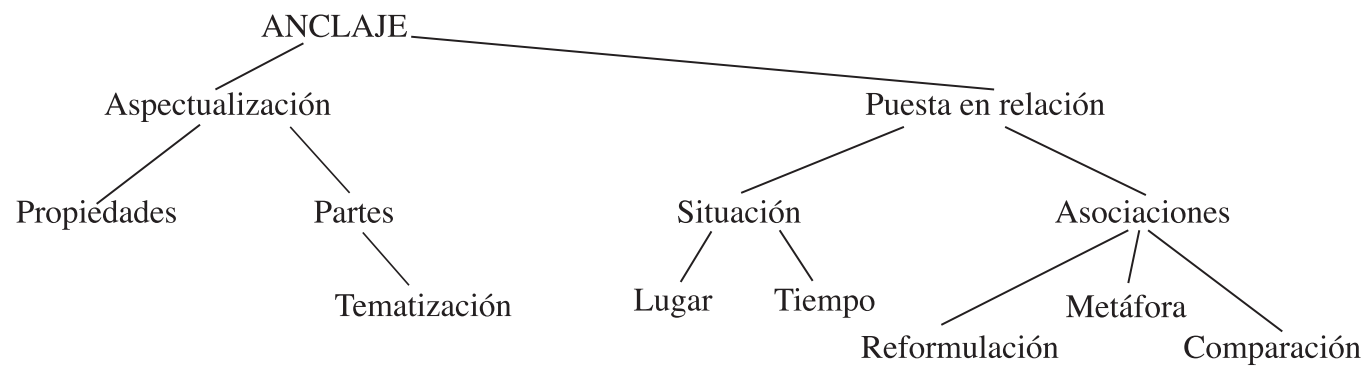


Así, por ejemplo, el anclaje es el punto de partida, palabra de entrada que organiza las demás proposiciones.

La aspectualización, por su parte, tiene como objetivo describir el producto desde el punto de vista de sus constituyentes y propiedades. Con este fin, el enunciador selecciona aquellas propiedades más atractivas y los componentes que impresionen más positivamente al destinatario. La descripción no debe ser excesivamente especializada o técnica para no desorientar o desmotivar al lector, al desdibujar el objeto descrito e ir en contra del propósito persuasivo del mensaje.

La puesta en relación, en cambio, relaciona el objeto descrito con otros objetos, en el tiempo y lugar en que se presentan, para definirlo, limitarlo o representarlo mejor. Con este propósito en mente, el enunciador usa frecuentemente la metáfora o la comparación, permitiéndole al destinatario conformar una imagen nítida y deseable del producto descrito, aunque las comparaciones pueden a veces resultar incompletas y deban ser cotejadas contextual o culturalmente.

En cuanto a la tematización, esta constituye un recurso mediante el cual el enunciador crea la progresión de la descripción para hacer avanzar el texto. Un elemento nuevo genera nuevas proposiciones descriptivas, en el que el nombre del producto juega un rol importantísimo, ya que asegura el anclaje inequívoco de los elementos descriptivos.

\section{Resultados y discusión}

El análisis del corpus muestra los siguientes resultados en cuanto a la configuración lingüística del anclaje, aspectualización, puesta en relación y tematización en los textos descriptivos de 30 avisos publicitarios de Internet.

\subsection{El anclaje}

En el caso de los avisos publicitarios farmacéuticos, el anclaje lo constituye frecuentemente el nombre del producto, que asume la forma de un nombre de fantasía que combina la sustancia base del producto con un sufijo llamativo. Este nombre propio se constituye en el título o tema clave, con frecuencia al comienzo del texto, aunque también retarda su aparición hasta el final, creando con ello un efecto de suspenso o de expectativa.

En la muestra analizada, se observaron los siguientes tipos de anclaje:

a. El nombre propio o de fantasía del producto, estructurado a partir de la sustancia base que lo compone.

\section{Ephedra $\rightarrow$ Ephedrine}

b. Una frase llamativa, sinónimo de energía y actividad y que, a la vez, da el nombre a la droga.

\section{On The Go}

c. Un anclaje desplazado, en el que el nombre del producto no se menciona sino hasta avanzado el texto o bien al final, como en el ejemplo a continuación. La introducción 
del producto se hace con el fin de anticipar los efectos supuestamente benéficos de su consumo.

Sustained energy boost up to ten hours! High speed conversion of Fat to Muscle! Appetite suppression and rapid weight loss! They are calling it the miracle plan of the new millennium! Dahlulin 500.

d. Apoyo de citas de fuentes autorizadas al introducir el producto con el fin de otorgarle credibilidad, como por ejemplo:

'estudios clínicos', 'D \& E Pharmaceuticals', 'scientific Research'..., etc.

e. Alusiones sucesivas al objeto descrito a través de emisiones reiteradas o mediante reformulación.

\section{An explosion of pure herbal dynamite $\rightarrow$ a blast of pure natural energy.}

Este recurso permite representaciones más sugerentes de la diversidad de percepción o de posibles interpretaciones del producto. Se ofrece, así, una perspectiva diferente a cada uno de los destinatarios, reformulada subjetivamente, cargada de intencionalidad.

Como se aprecia en estos ejemplos, la intencionalidad está dirigida a captar el interés de potenciales compradores que experimentan distintas motivaciones frente al producto. En ocasiones, el producto se perfila mediante diferentes remisiones, con el fin de brindar una representación más rica o sugerente en su percepción o interpretación. Dada la heterogeneidad del destinatario receptor, quien puede sentirse atraído por variadas motivaciones estéticas, médicas, de prevención, etc., cada elemento descriptivo profundiza sobre el anterior, o bien lo enfoca desde ángulos distintos y apela al comprador, destacando las diferentes supuestas virtudes del producto.

\subsection{Aspectualización}

Los resultados del análisis del corpus revelan que al elegir las características que el enunciador desea resaltar, prefiere aquellas que puedan hacer del producto algo único, que lo distinga de otros posibles productos similares en el mercado. Con este fin, emplea sustantivos, adjetivos, verbos y adverbios que apuntan a la unicidad y singularidad del producto ofrecido. Se le analoga con sustantivos que denotan un estado ideal de salud, belleza o bienestar.

\subsubsection{Sustantivos: explosion, energy(izer), boost, blast, high achievers, potency, alertness, vitality, discovery, endurance, benefits}

La elección del léxico busca destacar la singularidad del producto, creando preferentemente un enunciado sucinto, que pueda llegar a constituirse en un lema, fácil de memorizar. Todos los sustantivos empleados poseen valoración positiva y tienen que ver con conductas deseables de alcanzar: hiperproductividad, vitalidad, alto poder de ejecución, agilidad y agudeza mental, destreza, alta percepción. 
3.3.2. Adjetivos: strong, safe, potent, synergistic, pure, natural, unique, distinct, unrivalled, mega, healthy, good, superior, super, powerful, amazing, essential, delicious, peach/cherry flavour, impressive

En los textos analizados abunda la adjetivación en todas sus formas (calificativos, adjetivos pospuestos, frases preposicionales, cláusulas adjetivas, adjetivos en aposición, etc.). Estos describen las bondades, la forma de presentación, el grado de concentración, el sabor, etc.

El siguiente ejemplo ilustra núcleos nominales modificados por adjetivos que apuntan a despertar emociones y sentimientos en el destinatario:

- Nature's Ultra Boost combines impressive doses of... (adjetivos calificativos, impresionistas)

- $\quad$ Minerals [which is] combined with aminoacids and herbs (cláusula adjetiva)

- $\quad$ A daily nutritional supplement with phytonutrients and prostate supporting nutrients (frase preposicional)

- $\quad$ A balanced blend of twelve essential vitamins and minerals (frase preposicional)

- $\quad$ Energizers available without prescription (frase adjetiva en aposición)

- $\quad$ Liquid daily vitamins and minerals. Delicious peach flavour. Easy to use. All natural. Free of gluten and wheat by products. 16 ounces (Adjetivación anafórica a través de núcleos nominales y adjetivales)

\subsection{Puesta en relación}

En cuanto al proceso de puesta en relación, se observa que el enunciador sitúa el producto en un lugar y tiempo específico para definirlo, limitarlo o representarlo mejor, como se aprecia en el siguiente ejemplo:

Whether you are on the tennis court, on the job or on the town ...

Una revisión de los tiempos verbales más utilizados para describir las características del producto revela la presencia de aquellos de carácter durativo, especialmente el presente y el imperfecto. Los de mayor frecuencia en este tipo de corpus son el presente (simple y compuesto) del indicativo. Para conminar al destinatario a la acción, se emplean con alta frecuencia verbos de tipo directivo, conjugados en el modo imperativo: 'take' y 'use'.

- $\quad$ Take three tablets daily.

- Use it whenever you feel yourself dragging...

En esta puesta en relación, ocurren igualmente una variedad de verbos de estado, de acción y de proceso empleados en el posicionamiento del producto, siendo el de mayor frecuencia el verbo 'ser', pues los verbos atributivos y de apariencia (ser, estar, parecer) suelen expresar estados o apariencia ideales, resultado del uso del producto; se utilizan específicamente para denotar las propiedades benéficas de este en el proceso de puesta en relación (Bassols y Torrent 1997):

- $\quad$ Each capsule is an explosion of pure herbal dynamite

- $\quad$ Super Energy Herbal Formula is unrivalled in its synergistic punch! 
Las acciones típicas, en cambio, apuntan a perfilar acciones ordenadas cronológicamente que describen el efecto deseable, producto del consumo del objeto descrito ( sharpen, flood, make, act).

- Its high potency blend of energizers boosts your mental alertness, sharpens your senses and floods your body and mind with pure natural energy

- One capsule is all its takes to "pep up" with a blast of pure, natural energy

Los verbos que describen el proceso de puesta en relación buscan generar la confianza y credibilidad del destinatario (test, nourish, recharge, begin, increase, prove, pack, work)

- $\quad$ Examining these claims, modern researchers began testing a high-potency dahlia derivative, called inulin

- $\quad$ One tablet nourishes your cells and recharges your body and mind with super vitality

Muchos de estos verbos evalúan positivamente aquella propiedad que el enunciador desea destacar (enhance) y otros apelan a emociones (feel, want):

- Vital nutrients your body needs to enhance the growth of hair and nails.

Se observa también la presencia de verbos que remiten un dictum que convive con el presente, con testimonios que refuerzan el afán persuasivo del enunciador, como se ilustra en los siguientes casos:

- $\quad$ Athletes using Dahlulin tell us of their sustained energy boosts...

- $\quad$ Dieters say weight loss was increased as much as $25 \ldots$

Todos ellos contribuyen a que el consumidor perciba con precisión la relación entre las propiedades y las partes del producto descrito.

En la aspectualización y puesta en relación se observa tanto la existencia de adverbios de modo y de lugar en función referencial anafórica y catafórica (daily, dramatically, naturally, actually, entirely, only) como la presencia de frases yuxtapuestas conectadas por otros sistemas.

- $\quad$...whenever you feel yourself dragging, whenever your system needs a little herbal dynamite...

En la puesta en relación, el enunciador recurre a léxico de gran fuerza expresiva, lo que logra seleccionando palabras claves impactantes relacionadas con energía y poder; una sintaxis atractiva, el empleo de comparaciones y/o figuras de estilo, como la metáfora, cuya función es establecer una analogía entre dos referentes: una expresión literal y otra que tiene un parecido con ella, como se ilustra en los siguientes ejemplos:

- $\quad$ Each compact capsule is an explosion of pure herbal dynamite

- $\quad$ On the Go Plus keeps you bursting with energy and glowing with good health.

- $\quad$ Same formula as nationally advertised Theragram-m and at less than half the price! 
- DNE's 2001 Formula offers more Beta carotene and other antioxidants, aminoacids and other nutritional factors in a base of herbs and natural foods [than any other product].

Además de lo anterior, cabe destacar que en el proceso de puesta en relación de los elementos descritos, el producto ofrecido se presenta en una variedad de formas para captar diferentes segmentos del mercado potencial, tales como niños, ancianos, jóvenes o adultos. Con este propósito, la conformación linguiística del texto se ve reforzada con recursos complementarios, tales como imágenes de apoyo al texto, colores alusivos al producto o formas atractivas para el consumidor: Tabletas y cápsulas (adultos), jarabe (ancianos y bebés), gomitas (jóvenes) barras y figuras de animales (infantes), etc.

\title{
3.4. Tematización
}

El análisis de la tematización revela que, en el caso de las drogas ofrecidas, se destaca el arquetipo exitoso, el cuerpo ideal, el equilibrio saludable, la potencia en el rendimiento, la mente alerta, la producción máxima y los óptimos beneficios derivados de la combinación de estos. Por su parte, la repetición fija el tema descrito y propicia la cohesión, lo que no solo cohesiona el texto sino que lo hace avanzar progresivamente.

En las descripciones se aprecia una variedad de temas, contrario a la narración, donde se articulan con base en el mismo tema. La progresión temática es lineal, en la cual un rema se convierte en el nuevo tema de una nueva proposición, lo que indica la ocurrencia de nuevos núcleos que desarrollan nuevos predicados.

La finalidad o el propósito del texto guía la operación de puesta en relación de los elementos, como se aprecia en el siguiente ejemplo:

\section{What is Hoodia?}

\begin{abstract}
Hoodia Gordonii is a leafless, spiky succulent. The plant grows naturally in the Northern Cape, a province of South Africa, where it is registered as a protected species by Nature Conservation. This environmental agency included Hoodia Gordonii in its list for its effects as an appetite suppressant and mood enhancer. Patients have reported excellent results by using it as part of a weight loss program, leading many international companies making and selling Hoodia to consider it as a 'new miracle diet pill'. Western countries, the US and many European nations among them, have claimed that Hoodia is the 'new miracle diet ingredient'. Mass global interest has been shown for Hoodia since Pfizer, the international pharmaceutical giant, started to research Hoodia's potential to help people with obesity. There is strong evidence to suggest that Hoodia may become a worldwide answer to obesity, as studies have confirmed excellent results.
\end{abstract}

\section{Conclusiones}

El texto descriptivo de los anuncios publicitarios enviados a través de Internet presenta los rasgos típicos de los textos descriptivos generales, pero estructurados en forma más concisa y sintética. Se apoya en elementos efectistas, como imágenes y colores, a la vez que en el uso de un lenguaje impresionista para seducir al potencial comprador. La variedad de elementos estilísticos se combina mediante recursos de cohesión y de coherencia para dar forma al texto descriptivo-persuasivo. La referencia y la cohesión léxica ayudan a trabar la unidad del texto. 
Es frecuente el empleo de recursos anafóricos, como la pronominalización (personal, posesivos, demostrativos, relativos), como también la cohesión léxica, a través del recurso de repetición, de la sinominia, de la hiponimia, de la hiperoniminia, de la antonimia, etc.

Se utiliza un tipo de descripción más bien impresionista que apela a los sentidos y sentimientos del destinatario -frecuentemente a su ego- para provocar emociones y empatía con el anuncio. El elemento común en los avisos publicitarios de este tipo es entonces claramente la intención de convencer al destinatario de las bondades del producto y animarlo a suscribir una compra.

Típicamente el mensaje contiene imágenes que potencian el mensaje lingüístico y terminan por convencer a un destinatario dubitativo.

Si bien estos textos conservan los rasgos propios de los textos descriptivos generales, introducen un nuevo sesgo, como señala Gladys Dávalos ${ }^{6}$

Se trataría de un nuevo lenguaje, un nuevo código de lenguaje, casi secreto, casi entre cómplices de algo que, aparentemente, hasta puede ser un juego, pero que conlleva ciertos riesgos...

Ahora que el concepto de 'aldea global' se ha instalado en todos los ámbitos de nuestra cultura, cabe preguntarse si esta globalización alcanzará también al lenguaje cibernético. Es decir, está en marcha una nueva revolución lingüística que posiblemente alcance a la mayor parte de la comunidad virtual. Las posibilidades de la sintaxis y de la morfología, a la vez que la organización estructural del texto, definidas en términos de factores como cohesión, relevancia, estructura de los párrafos y la progresión lógica de las ideas, se universalizará en pro de un mensaje que apunte a un destinatario más universal, más homogéneo y más globalizado.

En este contexto, la publicidad ha pasado a ser una actividad omnipresente en los medios, modelando estereotipos culturales y homogeneizando respuestas, a la vez que condicionando conductas funcionales al mercado, avasallando identidades culturales locales. El discurso publicitario, inserto así en un mundo globalizado, cumple una labor instrumental a este y justifica su utilidad en la importancia de destacar y hacer llegar de la manera más nítida posible los mensajes a un destinatario/consumidor masivo de textos e imágenes publicitarias. Estamos, por lo tanto, ante la presencia de un mensaje cada vez más legitimado en amplias capas poblacionales cuyo acceso a internet se ha vuelto cada vez más masivo.

\section{Notas}

1. Esta ponencia fue enviada para ser publicada en la revista ONOMAZEIN, de la Pontificia Universidad Católica de Chile (2005).

2. www.undp.org/dpa/spanish/opciones/WSSD/Mbeki.pdf

3. www.esmas.com/noticierotelevisa, Agencia EFE, Colombia, 2003

4. Buy Meds online! Canadian Pharmacy [UP to 80\% off] Xanax, Vioxx, Viagra, Cialis, Valium and many more!Fast delivery! with wholesale prices!

-No Consultation!

-No Shipping Charge with most packages!

-No Prior Prescription needed!

-No appointments!

-No Waiting Rooms! 
-No embarassment!

-Private \& Confidential!

-Discreet Packaging!

-HUGe SaVINGS!

Your order will be packaged discreetly for your privacy and protection.

5. Subject: Get discount drugs without prescription

Discount generic drugs. save over $70 \%$

Todays specials,

Viagra, retails for $\$ 15$, we sell for $3 ! ! !$

Prozac, retails for $\$ 6$, we sell for $\$ 1.50$ !!

-Private Online ordering!

-World wide shipping!

-No Prescription required!!

6. Escobar, Raúl Tomás. 2003. Las mafias de las drogas. Buenos Aires: Editorial Internauta.

7. Samaniego, J. L. 2003. “Lenguaje y cibernética”. ONOMÁZEIN. 8: 257-260.

\section{Bibliografía}

Adam, J.M. 1992. Les textes: types et prototypes. Paris: Nathan.

1989. Le texte descriptif. Paris: Nathan.

Burdach, Ana María y Hernán Pons. 2003. "Modos y modalidades en el género publicitario de Seguros". Onomázein. 8: 9-18.

Burdach, A.M. 1999. Estudio lingüístico discursivo de los mensajes publicitarios de dos revistas: Española e Inglesa. Tesis doctoral: Pontificia Universidad Católica de Chile.

Dávalos Arze, Gladys. 2002. "El lenguaje ante el desafío de la comunicación moderna en la Sociedad de información". Discurso de incorporación como miembro de número a la Academia Boliviana de la Lengua.

Escobar, Raúl Tomás. 2003. Las mafias de las drogas. Buenos Aires: Editorial Internauta.

Samaniego, José Luis. 2003. “Lenguaje y cibernética”. Onomázein. 8: 257-260.

\section{Sitios}

Sitio web Internet. 2004. www.esmas.com/noticierotelevisa/televisa/agenciaefe/colombia.

Sitio web Internet. 2004. www.undp.org/dpa/spanish/opciones/wssd/Mbeki.pdf. 